\title{
INTRATHORACIC EMERGENCY TRACHEOTOMY FOR TREATMENT OF TRACHEAL FOREIGN BODY IN A YOUNG CAT
}

[Traqueotomia intratorácica de emergência para o tratamento de corpo estranho em uma gata jovem]

\author{
Ayne Murata Hayashi ${ }^{1 *}$, Silvana Unruh ${ }^{1}$, Viviane Sanches Galeazzi ${ }^{1}$, Patricia Bonifácio Flor ${ }^{1}$, Ana \\ Carolina Brandão Campos Fonseca Pinto², Julia Maria Matera ${ }^{2}$ \\ ${ }^{1}$ Médicas veterinárias - Hospital Veterinário, FMVZ-USP \\ ${ }^{2}$ Docentes - Departamento de Cirurgia, FMVZ-USP
}

\begin{abstract}
Tracheal foreign bodies are rare emergency events. Several noninvasive methods are described for removal, such as bronchoscopy combined with appropriate grasping equipment or Foley catheter and forceps guided by fluoroscopy. However, complications can occur like pneumothorax, pneumomediastinum and irresponsive dyspnea as well as failure. Thus, pre-sternal tracheotomy combined with endoscopy or thoracotomy are attempted. Female cat, 1 year old, $1.6 \mathrm{~kg}$ had diagnosis of foreign body $(0.7 \mathrm{x} 0.5 \mathrm{~cm})$ with morphology of bird cervical vertebra at carina area, presenting one week of dyspnea, worsening with radiographic exam. It was performed emergency thoracotomy at left fifth intercostal space, followed by tracheotomy between the tracheal rings immediately cranial to the carina, allowing forceps removal. No foreign body was observed at radiograph after eight days and the patient was clinically well. Although, less invasive methods are preferable, they are not always available and they are not free from failures, leading to emergency tracheotomy as described in the present case report.
\end{abstract}

Keywords: thoracotomy; dyspnea; feline.

RESUMO - Corpos estranhos traqueais são eventos raros e emergenciais. Vários métodos não invasivos são descritos para a sua remoção, como broncoscopia combinada com equipamento apropriado de preensão ou cateter de Foley e pinça guiados por fluoroscopia. Entretanto, complicações como pneumotórax, pneumomediastino e dispneia irresponsiva assim como insucessos podem ocorrer. Portanto, traqueotomia preesternal combinada com endoscopia ou toracotomia são tentativas viáveis. Gata, 1 ano, 1.6kg teve diagnóstico de corpo estranho $(0.7 \times 0.5 \mathrm{~cm})$ com morfologia de vértebra cervical de ave na região da carina. Apresentava há uma semana, dispnéia, piorando durante exame radiográfico. Foi realizado toracotomia de emergência no quinto espaço intercostal esquerdo, seguida de traqueotomia entre os anéis traqueais imediatamente cranial à carina, permitindo remoção por fórceps. Após oito dias, foi realizada radiografia controle e o paciente apresentava-se clinicamente bem. Embora, métodos menos invasivos sejam preferidos, não são isentos de falhas, necessitando toracotomia emergencial como a descrita no presente relato.

Palavras-Chave: toracotomia; dispneia; felino.

\footnotetext{
* Autor para correspondência. E-mail: aynevet@usp.br Recebido: 13 de agosto de 2016.

Aceito para publicação: 14 de setembro de 2016.
} 


\section{INTRODUCTION}

Tracheal foreign bodies are rare (Goodnight et al., 2010) and infrequently reported in cats (Johns et al., 2014). However, they are potentially lifethreatening clinical and surgical emergency cases. The surgical removal, after quick evaluation, diagnosis and promoting stabilization of dyspnea, represents treatment choice for the patients (Goodnight et al., 2010). Most tracheal foreign bodies in cats are located in the carina, on the other hand, small objects can move down to the distal airway (Johns et al., 2014). Sometimes, the cat can recover from general anesthesia more quickly than expected, and subsequently injure the endotracheal tube. It can result in aspiration of amputee portion and becomes a tracheal foreign body (Nuttel al., 2014).

However, cervical tracheal foreign body can be an uncommon cause of bronchopneumonia in a cat, if there is late diagnosis and the patient could have intermittent dyspnea (Johns et al., 2014). Inhalation of foreign objects to the distal airway can cause different levels of coughing, dyspnea, stridor, panic and cyanosis (Zambelli, 2006). One must make differential diagnosis with pneumomediastinum in cats, although it represents another unfrequently condition, mostly related to general anesthesia and endotracheal intubation with positive ventilation and less frequently, as a spontaneous presentation (Thomas \& Syring, 2013).

Several effective methods are described to remove every type of tracheal foreign bodies, including rigid or flexible bronchoscopy with grasping forceps or Foley urinary catheter passing alongside the bronchoscopy and inflated past the foreign body, vacuum extraction and the use of forceps with fluoroscopy (Goodnight et al., 2010; Nutt et al., 2014). Surgical treatment, including pre-sternal tracheotomy and endoscopy through the tracheostomy site, sometimes with a thoracotomy approach, has been described when the less invasive methods of removal failed (Nutt et al., 2014). Besides, bronchoscopy was related to promote pneumomediastinum, subcutaneous emphysema, oxygen irresponsive dyspnea and cyanosis, just after the removal of a calyx and stem fragments of a flower, cranial to the carina in a cat (Zambelli, 2006). Endoscopic retrieval of tracheal foreign body is one of the etiologies of pneumomediastinum in cats (Thomas \& Syring, 2013).

However, at veterinary clinics or hospitals without the endoscopy resource, it may be prudent to attempt to remove the foreign body with available tools, including passing a smaller cuffed endotracheal tube or a Foley urinary catheter into or through the displaced tube, inflating and then removing both tubes (Nutt et al., 2014). The other possibility is guiding a forceps by fluoroscopy, but it could increase trauma at adjacent tracheal wall, so it is more accurate to use bronchoscopy (Nutt et al., 2014).

This case report has the purpose of describing the diagnosis, clinical and surgical approaches of a foreign body at carina area in a young cat trachea

\section{CASE REPORT}

A female, one year old cat, $1.6 \mathrm{~kg}$, was attended presenting with apathy and dyspnea for seven days. The owner reported association of the event with ingestion of chicken bone. Moreover, it was observed unproductive cough for seven days, respiratory distress, exercise intolerance and inappetence for five days. There was trauma possibility. The cat had free access to the street and it was adopted when it had 30 days of age. The usual feeding was dry food and homemade food and there was no previous immunization. At clinical exam patient was alert, with a corporal score condition of $4 / 9$, respiratory rate of 32 movements/min, cardiac frequency of 204 beats/min, body temperature of $37.9^{\circ} \mathrm{C}$ and $5 \%$ dehydration, capillary refill time of 2 seconds, discrete mucopurulent nasal discharge, no cardiac murmur, but inspiratory wheezing at both hemi thorax and mixed dyspnea. At first attempt doing radiographs, the cat was submitted to oxygen therapy. After respiratory stabilization, thoracic radiographs were done. Images suggested presence of foreign body with bone density, $0.7 \times 0.5 \mathrm{~cm}$, with morphology of cervical bird vertebra located at the carina lumen (Figure 1).

Surgical approach was performed just after diagnosis. Pre-medication with meperidine $(3 \mathrm{mg} / \mathrm{kg})$ and induction with intravenous propofol $(5 \mathrm{mg} / \mathrm{kg})$ was performed followed by tracheal intubation. General anesthesia and maintanance was performed with isoflurane and fentanyl bolus $(2,5$ $\mathrm{mcg} / \mathrm{kg}$ ). Intercostal thoracotomy was performed on the fifth space. Trachea was identified after divulsion of mediastinum, just cranial to the heart base. Two 3.0 nylon $^{\mathrm{a}}$ surgical threads were positioned to sustain the tracheal rings cranial to the carina area. Between these tracheal rings, tracheotomy was performed to remove the foreign body (bone) with the help of right angle mixter forceps. Immediately after removal of the foreign body, the surgeon had tried to introduce the endotracheal tube at the tracheotomy site, to maintain ventilation and inhalatory anesthesia. However, it had failed. It was retrieved again the endotracheal tube oral insertion with success, passing through the tracheotomy site. At the same 
time, the surgical threads used previously to sustain the tracheal rings were attached together to approximate the tracheotomy site with appropriate apposition. Thoracorraphy with apposition of the fourth and fifth ribs were performed with three simple interrupted sutures using 3.0 nylon. Local bupivacaine infiltration was applied at adjacent intercostal muscle. Muscle and subcutaneous were approximated with continuous suture using 3.0 poliglecaprone. Skin suture was performed with interrupted sutures using 3.0 nylon $^{\mathrm{a}}$. Foley catheter was placed as thoracic tube for 24 hours to monitor air or liquid drainage, which was not present. Antibiotic therapy was performed during the intensive care period with ceftriaxone $30 \mathrm{mg} / \mathrm{kg} 12$ hours and metronidazole $10 \mathrm{mg} / \mathrm{kg} 12$ hours, dexamethasone $12.5 \mathrm{mg} / \mathrm{kg}$ and analgesia with methadone $0.2 \mathrm{mg} / \mathrm{kg} 8$ hours. After 24 hours of intensive care, it was prescribed oral medication for take home as follow: ranitidine $2 \mathrm{mg} / \mathrm{kg}$ and ondansetron $0.5 \mathrm{mg} / \mathrm{kg} 12$ hours during 2 days, and amoxacilin clavulonate $20 \mathrm{mg} / \mathrm{kg} 12$ hours during 10 days and tramadol $2 \mathrm{mg} / \mathrm{kg} 8$ hours during 3 days.

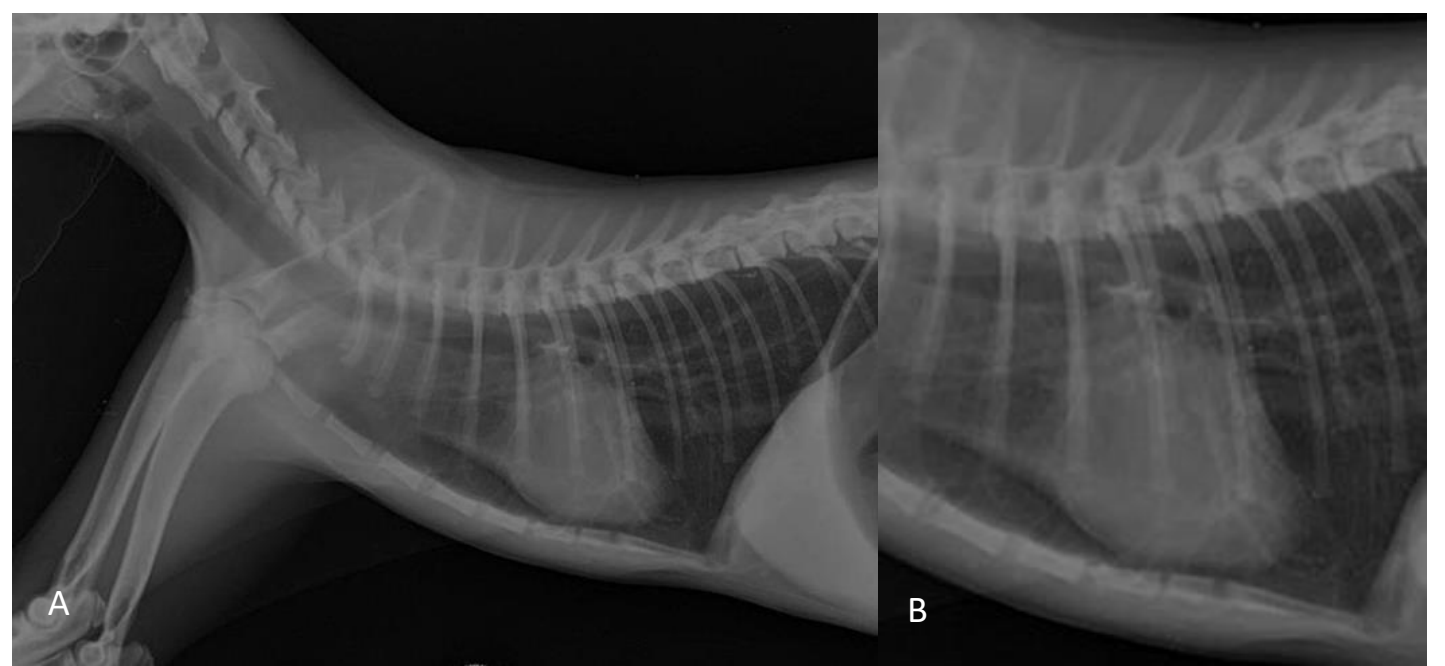

Figure 1. A) Right lateral radiographic view of the thorax of the cat. Presence of foreign body with bone density, $0.7 \times 0.5 \mathrm{~cm}$, with morphology of cervical bird vertebra located at the carina lumen, the pulmonary parenchyma is radiographically normal, and there is evidence of aerophagy. B) Enlarged image of right lateral radiographic view with the detailed foreign body at carina lumen (FMVZ/USP).

Control radiograph were taken after eight days (Figure 2) demonstrating no foreign body at carina, tracheal and carina lumen presented no

abnormalities radiographically. The patient presented no clinical alterations.

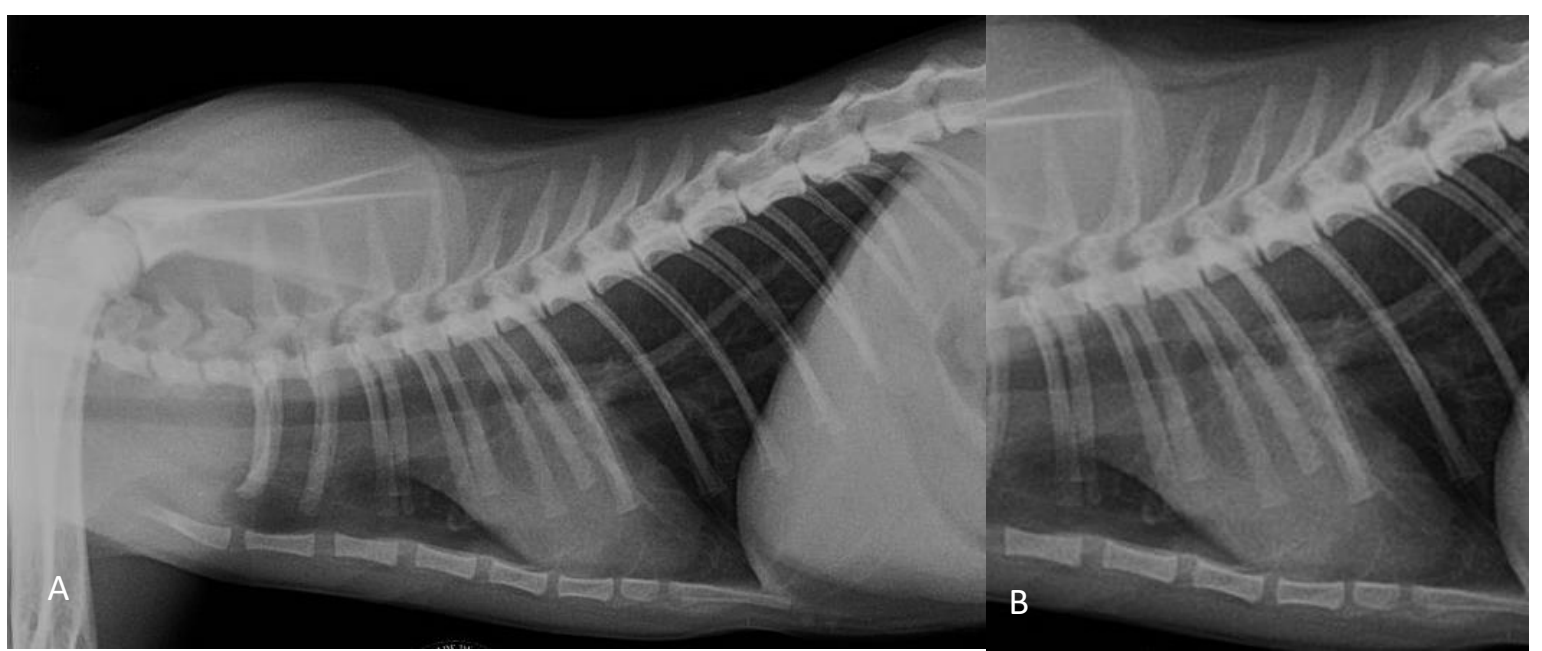

Figure 2. A) Right lateral radiographic view of the thorax of the cat- control radiograph after 8 days demonstrated no radiopaque foreign body at carina, tracheal and carina lumen presented no abnormalities and the pulmonary parenchyma is radiographically normal. B) Enlarged image of right lateral radiographic view shows no abnormalities at the carina area (FMVZ/USP). 


\section{DISCUSSION}

Tracheal foreign bodies in cats are infrequent. Several objects are described as needles, wood mulch, grass, tooth, gravel, bone, endotracheal tube fragment, bullet (Tivers \& Moore, 2006; Zambelli, 2006). Several less invasive techniques are described in literature to remove the tracheal foreign bodies, like bronchoscopy, aid with Foley catheter and fluoroscopy, endoscopy via pre-sternal tracheostomy (Goodnight et al., 2010; Tivers \& Moore, 2006; Nutt et al., 2014). However, whenever they are not available or it use results in failure, emergency thoracotomy must be performed, as it occurred at the present case report. These events represent emergency situations where the ability of quick evaluation, diagnosis and treatment of the respiratory distress are crucial to a favorable result.

Other surgical options are described in order to remove a foreign body (Nelson, 2003). Pushing the object further into the bronchial tree with subsequent lung lobectomy is not indicated if the object is too large or with inadequate morphology to completely enter the mainstem bronchus. Moreover, it can compromise the tracheal healing after lesion with the foreign body movement (Goodnight et al., 2010).

Interventional radiology is defined as the use of contemporary imaging techniques, frequently fluoroscopy, to guide catheters, guidewires of stents for therapeutic purposes (Goodnight et al., 2010). Retrospective study demonstrated the use of fluoroscopy with a forceps to guide the removal of a tracheal foreign bodies at carina or imediately cranial in 12 cats. The authors concluded that it is quick, safe and effective, and could be an option to bronchoscopy in cats or after the failure of its procedure. It can also avoid a thoracotomy (Tivers $\&$ Moore, 2006). New technique of removal of a tracheal foreign body in a nine-month old cat was described, after the attempt of removal by endoscopy without success due to the morphology and texture of the object. A balloon wedge pressure catheter guided by fluoroscopy with a guidewire inside, was advanced and positioned with the balloon caudal to the foreign body. After the removal of the guidewire, the balloon was inflated and a gentle traction was placed on the catheter until the object was moved and orally advanced to the larynx. Success was obtained and it was identified as a tetrahedral piece of landscaping gravel. Once the tracheal lumen was injured, the patient was submitted to oxygen therapy and intensive care until recovery (Goodnight et al., 2010). Although the use of catheter balloon is an alternative for endoscopy or thoracotomy, with the possibility of an uninterrupted ventilation during the procedure, we had decided in the case report presented here, to perform thoracotomy due to irregularity of the object and possibility of tracheal trauma if it was orally advanced to larynx.

Although several authors discuss about technical difficulty and potential morbidity associated with thoracotomy to remove tracheal foreign body, the present case report demonstrated that this is a feasible and quickly procedure, which must be done as soon as possible, once it is an emergency and life-threatening condition requiring immediate decision making.

Moreover, the minimally invasive techniques like endoscopy, frequently occlude the airway lumen, requiring repeated extubation and reintubation during a prolonged procedure. Others complications are pneumonia, cardiac arrest, laryngeal edema, pneumothorax. Infrequently ocurrences are pneumomediastinum, pleural effusion, atelectasia, bronchospasm, fever, tracheal laceration, post surgical stridor and hipoxia (Goodnight et al., 2010). In a study about etiology of secondary pneumomediastinum in cats, only $6 \%$ of the cases $(2 / 31)$ presented tracheal foreign body (Thomas \& Syring, 2013). There is a case report of pneumodiastinum, unilateral pneumothorax, subcutaneous emphysema and pneumoperitoneum after endoscopic removal of tracheal foreign body located immediately cranial to carina in a cat (Zambelli, 2006).

\section{CONCLUSION}

Less invasive methods to remove tracheal foreign body can be used, as rigid bronchoscopy or more preferable flexible and interventional radiology. However, they are not free of failure and need profissional training and specific equipment. So, it is necessary the training to emergency tracheotomy via intercostal thoracotomy as described in the present case report.

\section{REFERENCES}

GOODNIGHT, M. E.et al. Use of a unique method for removal foreigh body from trachea of a cat. Journal of American Veterinary Medical Association, v. 237, n. 6, p. 689-695, 2010.

JOHNS, S.et al. Tracheal foreign body and pneumonia in a cat: a near missed diagnosis. Journal of American Veterinary Medical Association, v. 50, n. 4, p. 273-277, 2014.

NELSON, A. W. Diseases of the trachea and bronchi. In: Slatter, D. (Ed). Textbook of small animal surgery. Philadelphia: WB Saunders Co, 2003. Vol 1, 862-864.

NUTT, L. K.et al. Manegement of dogs and cats with endotracheal tube traqueal foreign bodies. Canadian Veterinary Journal, v. 55, p. 564-568, 2014. 
THOMAS, E. K.; SYRING, R. S. Pneumomediatinum in cats: 45 cases (2000-2010).Journal of Veterinary Emergency and Critical Care, v. 23,n. 4, p. 429-435, 2013.

TIVERS, M. S.; MOORE, A. H. Tracheal foreign bodies in the cat and the use of fluoroscopy for removal: 12 cases. Journal of Small Animal Practice, v. 47, p. 155-159, 2006.

ZAMBELLI, A. B. Pneumomediastinum, pneumothorax and pneumoretroperitonium following endoscopic retrieval of a tracheal foreign body from a cat. Journal of South African Veterinary Association, v. 77, n. 1, 45-50,2006. 